
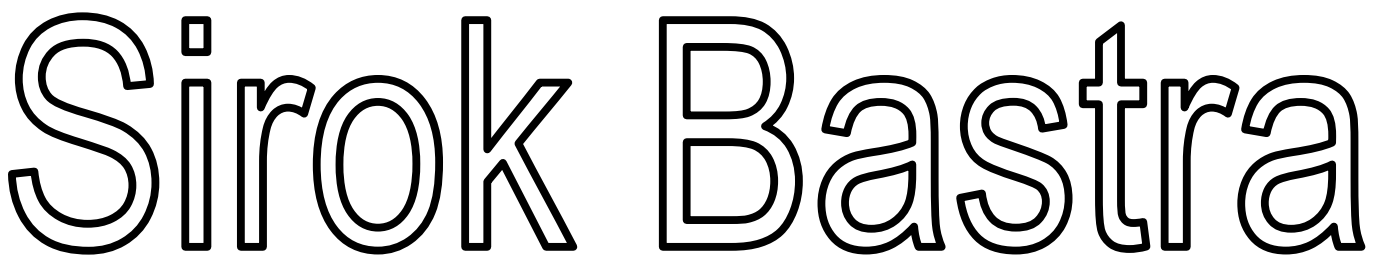

JURNAL ILMIAH KEBAHASAAN DAN KESASTRAAN

\begin{tabular}{|c|c|c|c|c|c|}
\hline $\begin{array}{c}\text { Sirok Bastra } \\
\text { Jurnal Kebahasaan dan } \\
\text { Kesastraan }\end{array}$ & Volume 2 & Nomor 2 & $\begin{array}{c}\text { Hlm. } \\
121-210\end{array}$ & $\begin{array}{l}\text { Pangkalpinang, } \\
\text { Desember 2014 }\end{array}$ & $\begin{array}{c}\text { ISSN } \\
2354-7200\end{array}$ \\
\hline
\end{tabular}

KANTOR BAHASA PROVINSI BANGKA BELITUNG 


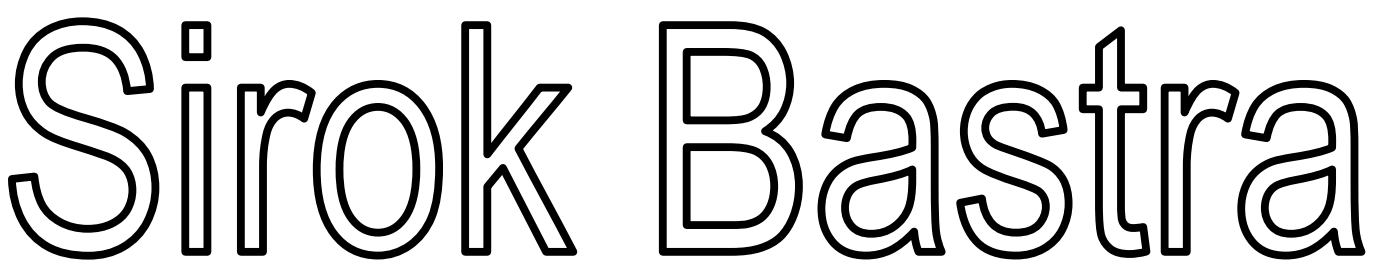

JURNAL ILMIAH KEBAHASAAN DAN KESASTRAAN

Jurnal ini merupakan wadah informasi mengenai kebahasan, kesastraan, dan pengajarannya yang memuat hasil penelitian, studi kepustakaan, dan tulisan ilmiah bidang kebahasan dan kesastraan serta pengajarannya. Sirok Bastra terbit dua kali setahun, yakni Juni dan Desember, serta terbit sejak Juni 2013.

\section{Penanggung Jawab}

Kepala Kantor Bahasa Provinsi Bangka Belitung Drs. Umar Solikhan, M.Hum.

Mitra Bestari

Prof. Dr. Agus Nuryatin, M.Hum. (Bidang Sastra dan Pengajarannya)

Prof. Amrin Saragih, Ph.D., M.A. (Bidang Bahasa dan Pengajarannya)

Dr. Felicia Nuradi Utorodewo, M.Hum. (Bidang Bahasa dan Pengajarannya)

Dr. Pujiharto, M.Hum. (Bidang Sastra dan Pengajarannya)

\section{Pemimpin Redaksi}

Rahmat Muhidin, S.S.

\section{Penyunting}

Prima Hariyanto, S.Hum.

\section{Perancang Sampul}

Feri Pristiawan, S.S.

\section{Kesekretariatan}

Khaliffitriansyah, S.Pd.

Dea Letriana Cesaria, S.Hum.

Lia Aprilina, S.Pd.

Andrian Priyatno, A.Md.

Elzam

\section{Alamat Redaksi dan Penerbit}

Kantor Bahasa Provinsi Bangka Belitung

Ruko Permata 7, Jalan Solihin G.P. Km 4, Kota Pangkalpinang, Prov. Kepulauan Bangka Belitung

Telp./Faks.: 0717-438455, Pos-el: sirokbastra@gmail.com, sirokbastra@kemdikbud.go.id

Pemuatan suatu tulisan dalam jurnal ini tidak berarti redaksi menyetujui isi tulisan tersebut. Isi tulisan menjadi tanggung jawab penulis. Tulisan telah ditinjau dan diulas oleh mitra bestari. Setiap karangan dalam jurnal ini dapat diperbanyak setelah mendapat izin tertulis dari penulis, redaksi, dan penerbit. 


\section{PENGANTAR}

Puji syukur ke hadirat Pemilik dan Pencipta semesta ini yang memiliki kuasa atas diri-Nya sendiri. Dialah Tuhan Yang Maha Esa yang telah memberikan rahmat dan hidayah-Nya sehingga Volume 2 Nomor 2 Jurnal Sirok Bastra Tahun 2014 dapat terbit tepat pada waktunya.

Pada edisi ini, dimuat sepuluh tulisan, yakni satu tulisan kebahasaan, satu tulisan pengajaran bahasa, dan delapan tulisan kesastraan. Dalam penelitiannya, Anitawati Bachtiar, Adek Dwi Oktaviantina, dan Rukmini membahas penggunaan alih kode dan campur kode pada dialog ubrug. Berdasarkan penelitian, ditemukan bentuk alih kode intern, berupa peralihan dari bahasa Jawa Serang menjadi Sunda Banten dan sebaliknya, serta alih kode metaforis dan situasional. Terdapat pula campur kode ke dalam yang berbentuk penyisipan kata pada kalimat yang diucapkan para pemain. Tujuan penggunaan alih kode dan campur kode itu adalah untuk memecah kekakuan saat pementasan, serta membangkitkan rasa humor agar penonton dapat terhibur.

Abdul Aziz melakukan penelitian yang bertujuan untuk mengupayakan peningkatan keterampilan siswa dalam menulis paragraf melalui metode inkuiri dengan menggunakan media audio pada siswa kelas $\mathrm{X}_{1}$ SMA DDI Alliritengae, Kabupaten Maros. Hasil penelitian menunjukkan bahwa metode inkuiri dengan menggunakan media audio dapat meningkatkan kemampuan menulis paragraf siswa kelas $\mathrm{X}_{1}$ SMA DDI Alliritengae, Kabupaten Maros pada tahap pelaksanaan dan tahap penilaian.

Dalam kajiannya, Tri Lia memaparkan nilai sosial dan budaya dalam cerita pendek "Sri Sumarah" karya Umar Kayam. Berdasarkan analisis, ditemukan beberapa nilai sosial budaya yang terdapat dalam cerita pendek ini, yaitu wayang dan stratifikasi sosial, masyarakat Jawa yang nrimo, sistem sapaan dalam masyarakat Jawa, mistik kejawen, masyarakat Jawa yang pembalas budi, keselarasan hidup masyarakat Jawa, dan latar politik PKI.

Dalam kajiannya, Dindin Samsudin membandingkan teka-teki (pertanyaan tradisional) yang terdapat di Provinsi Nanggroe Aceh Darussalam, yakni hiem dan yang terdapat di Provinsi Jawa Barat, yakni tatarucingan. Berdasarkan penelitian, terdapat beberapa hiem Aceh dan tatarucingan Sunda yang memiliki persamaan.

Dalam kajiannya, Kurniati membahas novel Orang-Orang Proyek karya Ahmad Tohari yang menurutnya berusaha menghadirkan sebuah realitas kemanusiaan, yakni melawan korupsi dan berbagai penyimpangan. Penulis menunjukkan bahwa di dalam novel tersebut terdapat kebenaran sosial. Karya ini memiliki sebab dan hasil kehebatan nilai artistik sebuah karya sastra (dengan dokumen sosialnya) sebagai potret kenyataan sosial.

Dalam penelitiannya, Sony Sukmawan membahas apokaliptisme sastra lisan Lereng Arjuna. Ciri-ciri yang terdapat dalam sastra lisan Lereng Arjuna dalam wujud (i) pemahlawanan tokoh mitologis dan sosok cikal bakal, trindih ukir, atau babat alas desa setempat; (ii) implikasi gagasan apokaliptik di balik latar penamaan desa, latar penamaan situs-situs purbakala, dan situs keramat alami; (iii) penamaan para-baureksa dalam mantra; serta (iv) pengungkapan apokaliptik sebagai pemulihan stabilitas alam melalui tindakan pencegahan yang persuasif.

Hestiyana membahas tema dan amanat cerita rakyat di Kecamatan Karang Intan, Kabupaten Banjar. Dalam penelitiannya, ditemukan tiga bentuk cerita rakyat, yaitu dongeng, legenda, dan mite. Cerita rakyat tersebut terdiri atas satu dongeng yang berjudul "Ular Tadung di Gunung Kiyau"; dua legenda berjudul "Asal Usul Nama Desa Karang Intan" dan "Asal Usul Nama Danau Purun"; dan satu mite berjudul "Pamandian Putri di Gunung Putra Bulu".

Dalam penelitiannya, Helmina Kastanya membahas tradisi lisan tatabuang manare dan badendang yang merupakan salah satu kekayaan sastra yang mengandung nilai estetika dalam pesta pernikahan masyarakat Pulau Ambon. Berdasarkan penelitian, bentuk tradisi lisan tatabuang manare dan badendang adalah prosesi berbalas pantun sambil menari diiringi alunan musik totobuang dan tifa. Tradisi ini berfungsi sebagai media penyatuan dua keluarga yang baru menjadi besan. Adapun nilai yang terkandung di dalamnya adalah nilai percintaan, kekeluargaan, dan sosial.

Dalam penelitiannya, Bagus Kurniawan membahas strategi pembacaan dekonstruksi karakter Arjuna sebagai lelananging jagad dalam lakon-lakon wayang purwa. Menurutnya, pemaknaan terhadap wayang masa kini mulai beragam, tidak hanya melalui dikotomi hitam-putih, tetapi juga melalui berbagai tafsir yang kemudian 
mendekonstruksi makna yang sudah mapan. Dalam tulisan ini, diuraikan strategi pembacaan secara dekonstruksi terhadap karakter Arjuna dengan menggunakan beberapa lakon wayang berbahasa Indonesia yang diterbitkan di majalah Cempala.

Mulawati mengkaji nilai karakter bangsa dalam nyanyian rakyat Muna di Provinsi Sulawesi Tenggara. Berdasarkan penelitian, unsur intrinsik nyanyian rakyat Muna menyiratkan nilai-nilai karakter bangsa seperti disiplin, selalu bekerja keras, mandiri, kreatif, dan toleransi.

Kami mengucapkan terima kasih kepada para penulis yang telah bersedia menerbitkan karya mereka pada edisi ini. Para penulis merupakan peneliti, pakar, dosen, guru, dan mahasiswa dari berbagai sekolah, perguruan tinggi, dan instansi. Terima kasih juga kami sampaikan kepada para mitra bestari yang telah memberi ulasan terhadap tulisan-tulisan yang masuk ke redaksi.

Demi memenuhi keberagaman isi dan penulis, Sirok Bastra membuka kesempatan bagi para peneliti dan penulis untuk menyampaikan hasil penelitian dan pemikiran mutakhir dalam bidang kebahasaan, kesastraan, dan pengajarannya.

Pangkalpinang, Desember 2014

\section{Tim Redaksi}




\section{UCAPAN TERIMA KASIH UNTUK MITRA BESTARI}

Redaksi Sirok Bastra mengucapkan terima kasih kepada para mitra bestari yang telah meninjau, menimbang, dan mengulas makalah-makalah yang diterbitkan dalam Sirok Bastra Volume 2 Nomor 2, edisi Desember 2014, yakni

\section{Prof. Dr. Agus Nuryatin, M.Hum.}

Bidang Sastra dan Pengajarannya

Universitas Negeri Semarang

Semarang, Jawa Tengah

Prof. Amrin Saragih, Ph.D., M.A.

Bidang Bahasa dan Pengajarannya

Universitas Negeri Medan

Medan, Sumatra Utara

\section{Dr. Felicia Nuradi Utorodewo, M.Hum.}

Bidang Bahasa dan Pengajarannya

Universitas Indonesia

Depok, Jawa Barat

\section{Dr. Pujiharto, M.Hum.}

Bidang Sastra dan Pengajarannya

Universitas Gadjah Mada

Yogyakarta, Daerah Istimewa Yogyakarta 


\section{DAFTAR ISI}

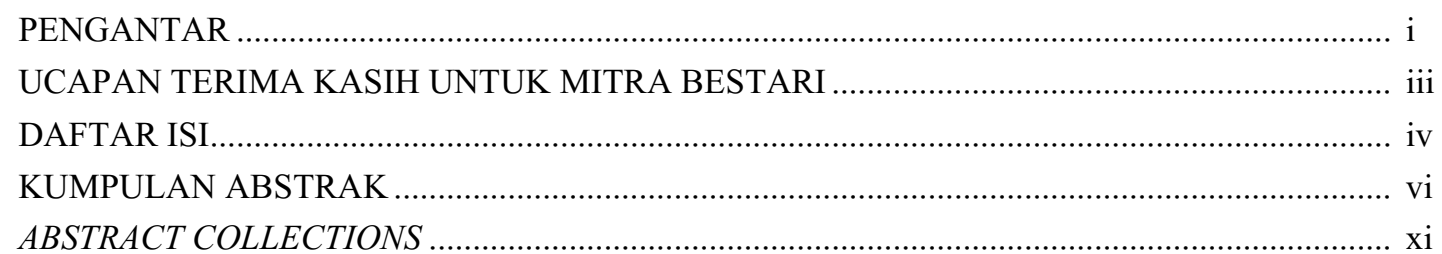

\section{UBRUG: KAJIAN SOSIOLINGUISTIK}

(Ubrug: Sociolinguistic Study)

Anitawati Bachtiar, Adek Dwi Oktaviantina, dan Rukmini $121-128$

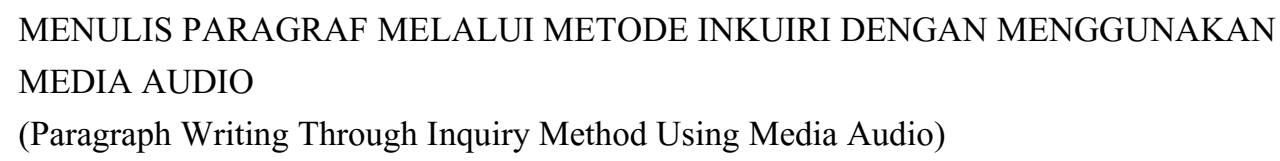

TEMA DAN AMANAT CERITA RAKYAT DI KECAMATAN KARANG INTAN, KABUPATEN BANJAR

(Theme and Message of Folklore in Karang Intan Subdistrict, Banjar Regency)

TATABUANG MANARE DAN BADENDANG DALAM PESTA PERNIKAHAN MASYARAKAT PULAU AMBON

(Tatabuang Manare and Badendang in Wedding Party of Ambon Island Society) 
MENGGUGAT ARJUNA SEBAGAI LELANANGING JAGAD: SEBUAH STRATEGI PEMBACAAN DEKONSTRUKSI KARAKTER ARJUNA DALAM LAKON-LAKON WAYANG PURWA

(Arjuna Sued as A Man of Universe: The Deconstruction of Reading Strategy for Arjuna's Character on Purwa Puppet Shows)

Bagus Kurniawan $193-200$

NILAI KARAKTER BANGSA DALAM NYANYIAN RAKYAT MUNA

(Nation Character Values in Munanese Folksong)

Mulawati $201-201$ 
Mulawati : Nilai Karakter Bangsa dalam Nyanyian Rakyat Muna

\title{
NILAI KARAKTER BANGSA DALAM NYANYIAN RAKYAT MUNA
}

Nation Character Values in Munanese Folksong

\author{
Mulawati \\ Kantor Bahasa Provinsi Sulawesi Tenggara \\ Kompleks Bumi Praja, Jalan Haluoleo, Kendari \\ Pos-el: mulawati.09@gmail.com
}

(diterima 29 Agustus 2014, disetujui 21 November 2014, revisi terakhir 8 Desember 2014)

\begin{abstract}
Abstrak
Beberapa tahun terakhir, nilai karakter bangsa menjadi fokus sistem pendidikan di negara kita. Nilai-nilai ini, sebagian, dapat diperoleh dalam sastra lisan atau tradisional di berbagai etnis yang ada di Indonesia. Artikel ini mendiskusikan salah satu tradisi lisan, yakni berupa nyanyian rakyat Muna di Provinsi Sulawesi Tenggara. Nyanyian menjadi suatu media yang digunakan untuk mengungkapkan perasaan, petuah-petuah, sindiran, dan gagasan-gagasan lainnya. Artikel ini juga mengungkapkan nilai-nilai karakter bangsa dalam nyanyian rakyat Muna. Setelah ditelaah, unsur intrinsik nyanyian rakyat Muna menyiratkan nilai-nilai karakter bangsa seperti disiplin, selalu bekerja keras, mandiri, kreatif, dan toleransi.
\end{abstract}

Kata-kata kunci: nilai karakter bangsa, nyanyian rakyat Muna

\begin{abstract}
Abstrak
Some recent years, nation character value becomes the focus of our education system in our country. Some of these values can be acquired in traditional or oral literature in some ethnics in Indonesia. This article discusses one of oral tradition, namely Muna's folk song in south-east Sulawesi Province. Folk song becomes a media used to express feeling, religious advice, satire, and other ideas. This article also expresses nation character value in Muna's folk song. After being studied, the intrinsic value of Muna's folk song implies nation charater values such as discipline, hardworking, independent, creative, and tolerance.
\end{abstract}

Keywords: nation character value, Muna folksong

\section{PENDAHULUAN}

\subsection{Latar Belakang}

“Anak SMP Kok Bawa Celurit?" merupakan salah satu judul artikel dalam www.kompas.com. Seorang pelajar SMP YWKA, Manggarai, Jakarta Selatan, NA (15) benar-benar tidak dapat ditiru. Saat anak lain berangkat ke sekolah dengan tujuan mencari ilmu, NA tawuran dengan puluhan pelajar lain di kawasan Jembatan Item, Jatinegara, Jakarta Timur. Saat tawuran, NA juga membekali diri dengan sebilah celurit hingga ia harus berurusan dengan petugas Polsektro Jatinegara. NA bersama sejumlah rekannya melakukan tawuran dengan kelompok pelajar lain di Jalan Jatinegara Timur (www.kompas.com). Menurut data Kepolisian Resor
Metro Jakarta Pusat, terjadi 20 kali tawuran sejak Januari hingga September 2009.

Sampai kini, tawuran antarpelajar masih saja terjadi di berbagai kota besar. Namun, belum ada solusi menyeluruh untuk mengatasinya, terutama di kota-kota besar seperti DKI Jakarta. Sebagai contoh, pada tahun 2011, baku lempar baik antarwarga maupun pelajar masih terjadi di sejumlah tempat, seperti di Kecamatan Johar Baru, Kecamatan Senen, dan Jalan Kramat Raya (www.kompas.com).

Selain tawuran antarpelajar, berbagai permasalahan sosial, seperti korupsi, kini justru terjadi dengan intensitas yang tinggi. Melalui berbagai media elektronik dan media cetak, kita masih disuguhi beritaberita tentang korupsi yang dilakukan layaknya 
kebiasaan sehari-hari. Kasus bailout century, penggelapan pajak oleh Gayus Tambunan, korupsi pembangunan sarana pesta olahraga Sea Games merupakan beberapa contoh saja dari banyak korupsi yang telah dan sedang hangat dibicarakan oleh media massa. Pejabat legislatif dan eksekutif berbondongbondong mengunjungi gedung KPK sebagai tersangka.

Apakah memang sudah semakin parah nilai-nilai moral di kalangan masyarakat, baik dari generasi muda maupun tua, baik di kalangan pejabat, pelajar, politisi dan kelompok lainnya? Tawuran pelajar dan korupsi yang kini menjadi semacam parade menunjukkan semakin rendahnya moral yang ditunjukkan oleh berbagai kelompok masyarakat. Tindakan untuk tetap menjunjung tinggi nilai-nilai moral sepertinya tergilas dan tergantikan oleh kekerasan fisik melalui tawuran maupun kekerasan nonfisik melalui tindakan korupsi.

Persoalan rendahnya nilai-nilai moral dalam kehidupan sehari-hari telah menjadi perhatian pemerintah, terutama Kementerian Pendidikan sebab masalah moral menjadi bagian yang tidak terpisahkan dari sistem pendidikan yang dianut oleh negara kita. Menurut Dewey, pendidikan adalah proses membentuk manusia baru melalui perantara karakter dan fitrah' serta dengan mencontoh peninggalan-peninggalan budaya lama masyarakat manusia. Menurut Sardiman (2006), salah satu tujuan pendidikan adalah subjek belajar atau siswa mampu mengombinasikan dua pengetahuan (atau lebih) ke dalam suatu pengertian baru, baik keterampilan, pengetahuan, konsep maupun sikap atau tingkah laku.

Selain itu, pendidikan adalah proses yang dialami manusia sepanjang hayat. Pendidikan lebih dari sekadar pengajaran karena pendidikan menyatukan beberapa hal yaitu ajaran, tuntunan, dan bimbingan mengenai moral dan kecerdasan pikiran. Sementara itu, pengajaran hanyalah kegiatan transfer ilmu. Dalam pendidikan juga dilakukan transformasi nilai dan pembentukan karakter dengan segala aspek yang dicakupnya sehingga manusia dapat menemukan jati dirinya (Aziz, 2011).

Berkaitan dengan pengertian pendidikan dalam paragraf sebelumnya, beberapa tahun terakhir telah digagas model pendidikan berkarakter bangsa. Hal ini didasari oleh kekhawatiran sejumlah pakar akan terjadinya lost generation di negara kita. Pemerintah mulai mengagas pendidikan dan kegiatan-kegiatan yang bertujuan meningkatkan karakter bangsa.

Tulisan ini bukan membahas cara-cara yang dilakukan pemerintah untuk mengembalikan nilai-nilai karakter bangsa bagi masyarakat Indonesia. Penulis membahas model penyampaian nilai karakter bangsa dan kebaikan melalui karya sastra. Menurut Untoro (2009), karya sastra dianggap mampu membawa perubahan dan mengandung ajaran atau pedoman hidup sehingga tidak diragukan lagi bahwa karya sastra memiliki fungsi sosial yang tinggi.

\subsection{Masalah}

Karya sastra dapat diklasifikasikan menjadi sastra modern dan sastra tradisional atau sastra lisan. Penulis berupaya mendiskusikan bentuk nyanyian rakyat yang terdapat dalam nyanyian rakyat Muna dan nilai-nilai karakter bangsa yang terdeskripsi dalam nyanyian rakyat Muna.

\subsection{Tujuan}

Dengan latar belakang yang telah dipaparkan di atas, penulis bermaksud membahas nilai-nilai karakter bangsa yang terdapat dalam nyanyian rakyat Muna. Hal ini mengingat bahwa sebagian besar nilai-nilai karakter dan keluhuran budi pekerti bangsa dapat kita peroleh melalui kekayaan tradisi lisan yang salah satunya berupa nyanyian rakyat.

\subsection{Manfaat}

Tulisan ini mendiskusikan model penyampaian nilai-nilai karakter bangsa melalui sastra tradisional, yaitu nyanyian rakyat yang telah banyak ditinggalkan oleh sebagian masyarakat kita. Saat ini, masyarakat lebih banyak mengadopsi nilai-nilai modern karena merasa bahwa tradisi lisan adalah cara yang telah kedaluwarsa.

Tulisan ini berupaya mencerahkan pemikiran sebagian masyarakat yang telah meninggalkan tradisi lisan mereka. Padahal, nilai-nilai kebaikan juga dapat diperoleh dalam tradisi lisan berupa nyanyian rakyat yang ada di negeri kita. Tradisi lisan berupa nyanyian 
rakyat telah digunakan para pendahulu kita lewat lantunan nyanyian sebelum tidur.

\subsection{Metode}

Data penelitian ini diperoleh dengan menggunakan metode kepustakaaan, yaitu mengambil beberapa nyanyian rakyat Muna yang telah dikumpulkan oleh Tim Penelitian Nyanyian Rakyat Muna tahun 2010.

Suku Muna yang ada di Provinsi Sulawesi Tenggara sesungguhnya memiliki ragam nyanyian rakyat yang digunakan dalam setiap aktivitas mereka. Data yang diambil oleh penulis adalah nyanyian rakyat yang digunakan sebagai nyanyian pengantar tidur, nyanyian nasihat orangtua kepada anak, dan nyanyian yang mengungkapkan kasih sayang anak pada orangtuanya.

Metode yang digunakan dalam penelitian ini adalah metode deskriptif analitis. Penulis mendeskripsikan dan menganalisis makna yang terkandung dalam nyanyian rakyat Muna. Sebuah nyanyian mengandung berbagai permasalahan dalam masyarakat tertentu, seperti masalah sosial, agama, tradisi, ekonomi, atau masalah politik yang terjadi pada masanya. Nyanyian rakyat yang dilantunkan bukan semata-mata hanya untuk menjalankan fungsi menghibur dari sebuah karya seni sastra, tetapi terdapat pesan khusus yang ingin disampaikan melalui nyanyian. Analisis data dilakukan dengan langkah-langkah sebagai berikut.

1. Syair nyanyian dianalisis ke dalam unsur-unsur dengan memerhatikan keterkaitan hubungan antarunsur-unsur tersebut secara keseluruhan.

2. Setelah syair dianalisis ke dalam unsur-unsurnya, dilakukan pemaknaan yang dihubungkan dengan nilai-nilai karakter bangsa.

3. Makna-makna yang telah ditemukan selanjutnya dipaparkan secara induktif.

\section{KERANGKA TEORI}

\subsection{Unsur-Unsur Sastra Lisan}

Jan Harold Brunvand (dalam Danandjaja, 1986:141), menyatakan bahwa nyanyian rakyat adalah salah satu genre atau bentuk folklor yang terdiri atas kata-kata dan lagu yang beredar secara lisan di antara anggota kolektif tertentu, berbentuk tradisional, serta banyak mempunyai varian. Nyanyian rakyat berasal dari bermacam sumber dan timbul dalam berbagai macam media. Walaupun demikian, identitasnya masih dapat kita kenali karena masih ada varian folklor yang beredar dalam peredaran lisan (oral transmission).

Secara umum sastra lisan merupakan unsur-unsur budaya yang dihasilkan oleh masyarakat di masa lampau yang mencakup bentuk ujaran, adat istiadat, atau perilaku lainnya, di antaranya cerita rakyat, nyanyian rakyat, tarian, permainan, dan peralatan atau benda seperti bangunan.

Menurut Muhammad Takari (2013:2), sastra lisan adalah sebuah karya sastra yang diwariskan terutama melalui aspek kelisanan (oral tradition). Unsur sastra lisan mencakup semua unsur kebudayaan manusia, baik sistem religi, bahasa, teknologi, ekonomi, seni, organisasi, dan pendidikan.

\subsection{Nyanyian Rakyat Muna}

Nyanyian rakyat adalah tradisi lisan yang dimiliki oleh hampir seluruh daerah yang ada di Indonesia. Menurut Jan Harold Brunvand (dalam Danandjaja, 1986), nyanyian rakyat adalah salah satu genre atau bentuk folklor yang terdiri atas kata-kata dan lagu yang beredar secara lisan di antara anggota kolektif tertentu, berbentuk tradisional, serta banyak mempunyai varian. Nyanyian rakyat berasal dari bermacam sumber dan timbul dalam berbagai macam media.

Di Sulawesi Tenggara, khususnya Kabupaten Muna juga dikenal beberapa bentuk nyanyian rakyat. Penulis tertarik mendiskusikan nyanyian rakyat Muna, yakni nyanyian pengantar tidur, nyanyian orangtua untuk anak, dan nyanyian anak untuk orangtua. Hal ini dilakukan karena nyanyian-nyanyian ini masih digunakan hingga saat ini.

Masyarakat Muna di Sulawesi Tenggara memiliki berbagai jenis sastra lisan, baik yang bercorak cerita maupun yang bercorak bukan cerita. Sastra lisan bercorak cerita meliputi legenda, dongeng, fabel, mite, dan sage. Jenis sastra lisan bercorak bukan cerita dikenal dengan sebutan kantola, nyanyian rakyat, ungkapan tradisional, teka-teki, dan sebagainya.

Kantola adalah sastra lisan Muna berbentuk pantun yang sangat digemari oleh masyarakat Muna dan merupakan budaya Muna yang sangat unik. Kantola 
biasa dilaksanakan dalam berbagai acara hajatan, acara pesta panen, dan sebagainya. Pantun yang dibawakan oleh setiap kelompok terdiri atas beberapa syair yang dimulai dengan syair wabhintoli dan diakhiri dengan syair salapasi.

Nyanyian rakyat Muna (selanjutnya disebut NRM) termasuk produk budaya masyarakat Muna yang tidak dapat dilepaskan dari berbagai aspek kehidupan masyarakat, baik aspek sosial maupun spiritual. Selain sebagai wadah atau sarana untuk mengungkapkan perasaan, NRM juga menjadi sarana yang digunakan untuk suatu kegiatan yang sifatnya ritual, seperti pengobatan penyakit atau pemanggilan roh. Eksistensinya sudah sedemikian mendalam menyatu dan bersemayam dalam jiwa dan watak masyarakat Muna. Penggunaan NRM dalam pengobatan penyakit tertentu memberikan sugesti kesembuhan bagi orang yang meyakininya. Sugesti tersebut memberikan ketenangan jiwa dan kedamaian. Oleh karena itu, NRM yang ditujukan untuk ritual tertentu diupayakan selalu dituturkan dalam keadaan yang hening, pikiran yang tenang, dan dijauhkan dari kebisingan yang mungkin dapat mengganggu (Rahmawati, dkk., 2010).

Selain kantola, masyarakat Muna juga memiliki kekayaan sastra lisan berupa nyanyian rakyat. Nyanyian rakyat (folksong) merupakan salah satu bentuk sastra tradisional yang banyak dikenal dan dinyanyikan hingga kini. Sebagai salah satu bentuk kesenian tradisional, pada umumnya nyanyian rakyat tidak diketahui penciptanya. Hal ini karena saat nyanyian itu diciptakan, rasa kebersamaan masih jauh lebih dipentingkan daripada kepentingan individual. Pewarisan nyanyian rakyat dilakukan secara lisan dan turun-temurun. Pada umumnya, anggota masyarakat pemilik nyanyian itu mempunyai perasaan memiliki (sense of belonging) yang amat dalam terhadap berbagai nyanyian rakyat daerah. Oleh karena itu, nyanyian rakyat juga dipandang sebagai salah satu identitas masyarakat pendukungnya.

Nyanyian rakyat dapat begitu meresap dalam hati anggota masyarakat pendukungnya, antara lain disebabkan mereka telah terbiasa mendengarkan nyanyian itu sejak masih bayi, masih kanak-kanak, dan juga ikut menyanyikannya. Nyanyian menjadi sebuah media bagi masyarakat sebagai pengungkap perasaan, petuah-petuah, sindiran, dan gagasan-gagasan lainnya. Seorang ibu berusaha menidurkan dan menenangkan anaknya yang sedang menangis dengan nyanyian. Seorang pemuda atau pemudi yang sedang memendam perasaan pada seseorang biasanya mengungkapkan perasaan hati lewat nyanyian-nyanyian yang bertema asmara. Seseorang yang sedang berada di perantauan menuangkan kerinduannya kepada kampung halaman lewat syair-syair yang menyayat hati, dan sebagainya. Singkatnya, nyanyian rakyat menjadi sarana untuk berekspresi bagi setiap orang yang bisa dilakukan setiap saat dan dalam semua keadaan.

NRM telah menjadi objek kajian yang dilakukan oleh beberapa orang. Penelitian terdahulu yang berhubungan langsung dengan NRM dilakukan pada tahun 2011, oleh staf Kantor Bahasa Provinsi Sulawesi Tenggara yaitu Rahmawati, S.S., Zakiyah M. Husba, S.S., dan Heksa Biopsi P.H., S.S. Penelitian ini menelaah makna dan fungsi NRM dengan pendekatan hermeneutika. Penelitian ini menyimpulkan bahwa secara keseluruhan NRM memiliki kekhususan fungsi, nilai dan makna dalam setiap jenisnya. Bagi masyarakat Muna, nyanyian rakyat merupakan tradisi lisan yang dilakukan secara turun-temurun yang fungsi dan manfaatnya dapat dirasakan dalam berbagai aktivitas. Oleh karena itu, nyanyian rakyat telah menjadi satu bagian dalam struktur kehidupan masyarakat yang akan terus diwariskan oleh masyarakat penuturnya.

Selain itu, tulisan La Kimi Batoa berjudul Sastra Tradisional Daerah Muna (2003) berisi uraian tentang contoh berbagai jenis syair-syair daerah Muna. Selain itu, beberapa contoh NRM dapat pula dijumpai dalam buku Sejarah Kebudayaan dan Kerajaan Muna karangan J. Couvreur. Penelitian lainnya yang mengangkat objek kajian NRM adalah penelitian yang berjudul "Sastra Lisan Muna" yang dilakukan oleh Ader Laepe, dkk. (2004). Penelitian ini hanya berfokus pada telaah lirik kantola dengan menggunakan teori semiotika dalam membedah simbol. 


\subsection{Nilai Karakter Bangsa}

Pendidikan karakter bukanlah hal baru dalam sejarah manusia. Orangtua telah melakukannya sejak dulu tanpa lembaga formal. Mereka telah berusaha mendidik anak-anak mereka agar menjadi anak baik menurut norma-norma yang berlaku dalam budaya mereka. Menurut Tim Pakar Yayasan Jati Diri Bangsa (Gede Raka, dkk., 2011), surutnya perhatian terhadap pembinaan karakter bermula sejak terjadinya revolusi industri di Eropa. Gejala ini juga terjadi di negara kita.

Menurut Yahya Khan (2010), pendidikan karakter mengajarkan kebiasaan cara berpikir dan perilaku yang membantu individu untuk hidup dan bekerja bersama sebagai keluarga, masyarakat, dan bernegara, serta membantu mereka untuk membuat keputusan yang dapat dipertanggungjawabkan. Jenis pendidikan ini terbagi empat, yaitu (1) pendidikan karakter berbasis nilai religius, (2) pendidikan karakter berbasis nilai budaya, (3) pendidikan karakter berbasis lingkungan, dan (4) pendidikan karakter berbasis potensi diri. Dengan demikian, model penyampaian nilai-nilai karakter bangsa dengan nyanyian rakyat termasuk dalam jenis pendidikan karakter berbasis nilai budaya.

Nyanyian rakyat dalam makalah ini berhubungan dengan beberapa nilai-nilai dalam karakter bangsa. Ada delapan belas nilai-nilai dalam pengembangan pendidikan budaya dan karakter bangsa yang dibuat oleh Kementerian Pendidikan Nasional sebagai berikut.

1. Religius; sikap dan perilaku patuh dalam melaksanakan ajaran agama yang dianutnya, toleran terhadap pelaksanaan ibadah agama lain, dan hidup rukun dengan pemeluk agama lain.

2. Jujur; perilaku yang didasarkan pada upaya menjadikan dirinya sebagai orang yang selalu dapat dipercaya dalam perkataan, tindakan, dan pekerjaan.

3. Toleransi; sikap dan tindakan yang menghargai perbedaan agama, suku, etnis, pendapat, sikap, dan tindakan orang lain yang berbeda dari dirinya.

4. Disiplin; tindakan yang menunjukkan perilaku tertib dan patuh pada berbagai ketentuan dan peraturan.

5. Kerja keras; perilaku yang menunjukkan upaya sungguh-sungguh dalam mengatasi berbagai hambatan belajar dan tugas, serta menyelesaikan tugas dengan sebaik-baiknya.

6. Kreatif; berpikir dan melakukan sesuatu untuk menghasilkan cara atau hasil baru dari sesuatu yang telah dimiliki.

7. Mandiri; sikap dan perilaku yang tidak mudah tergantung pada orang lain dalam menyelesaikan tugas-tugas.

8. Demokratis; cara berpikir, bersikap, dan bertindak yang menilai sama hak dan kewajiban dirinya dan orang lain.

9. Rasa ingin tahu; sikap dan tindakan yang selalu berupaya untuk mengetahui lebih mendalam dan meluas dari sesuatu yang dipelajarinya, dilihat, dan didengar.

10. Semangat kebangsaan; cara berpikir, bertindak, dan berwawasan yang menempatkan kepentingan bangsa dan negara di atas kepentingan diri dan kelompoknya.

11. Cinta tanah air; cara berpikir, bersikap, dan berbuat yang menunjukkan kesetiaan, kepedulian, dan penghargaan yang tinggi terhadap bahasa, lingkungan fisik, sosial, budaya, ekonomi, dan politik bangsa.

12. Menghargai prestasi; sikap dan tindakan yang mendorong dirinya untuk menghasilkan sesuatu yang berguna bagi masyarakat dan mengakui serta menghormati keberhasilan orang lain.

13. Bersahabat/komuniktif; tindakan yang memperlihatkan rasa senang berbicara, bergaul, dan bekerja sama dengan orang lain.

14. Cinta damai; sikap, perkataan, dan tindakan yang menyebabkan orang lain merasa senang dan aman atas kehadiran dirinya.

15. Gemar membaca; kebiasaan menyediakan waktu untuk membaca berbagai bacaan yang memberikan kebajikan bagi dirinya.

16. Peduli lingkungan; sikap dan tindakan yang selalu berupaya mencegah kerusakan pada lingkungan alam di sekitarnya dan mengembangkan upayaupaya untuk memperbaiki kerusakan alam yang sudah terjadi. 
17. Peduli sosial; sikap dan tindakan yang selalu ingin memberi bantuan pada orang lain dan masyarakat yang membutuhkan.

18. Tanggung jawab; sikap dan perilaku seseorang untuk melaksanakan tugas dan kewajibannya, yang seharusnya dia lakukan, terhadap diri sendiri, masyarakat, lingkungan (alam, sosial dan budaya), negara dan Tuhan Yang Maha Esa.

(http://rumahinspirasi.com/18-nilai-dalampendidikan-karakter-bangsa).

\section{HASIL DAN PEMBAHASAN}

\subsection{Nilai Karakter Bangsa dalam Nyanyian Menidurkan Anak pada Golongan Maradika dan Budak}

Masyarakat Muna termasuk kelompok masyarakat yang masih dipengaruhi kuat oleh paham feodalisme. Akibatnya, perbedaan kelas sosial masih kuat dalam kehidupan masyarakat. Golongan sosial dalam masyarakat Muna terdiri atas empat golongan, yaitu golongan La Ode, Walaka, Maradika, dan budak. Perbedaan strata sosial tersebut sangat mewarnai berbagai aspek kehidupan masyarakat, tidak terkecuali pada nyanyian-nyanyian pengantar tidur untuk anak. Berikut kutipan nyanyian tersebut.

nabhalamo namandemo natikambo-kambowamo.

nabhalamo namandemo natiala ngkawasamo

ale!ale!ale! wambhebhele labhala maka mbedhano

\section{Terjemahan}

kalau saya punya anak sudah besar akan dibawa-bawa raja-raja

besarlah dan menjadi pandai supaya bisa saja mengambil pekerjaan yang lain

sayang! sayang! sayang! wambhebhele bila besar maka saya menjadi senang

Nyanyian di atas menunjukkan bahwa jiwa pengabdian yang dimiliki oleh masyarakat Muna terhadap raja atau keturunan raja sangat besar. Kewajiban mengabdi terhadap keluarga raja atau mereka yang berasal dari golongan $L a$ Ode menjadi sesuatu yang sangat penting dalam masyarakat. Kesediaan untuk mengabdi tersebut terungkap pula lewat nyanyian pengantar tidur yang dinyanyikan seorang ibu dari kalangan Maradika dan budak saat menidurkan anak.

Pada larik pertama si ibu mengungkapkan keinginannya, bahwa ketika anaknya beranjak dewasa, anak tersebut pun akan patuh dan terus mengabdi kepada rajanya. Lirik nabhalamo namandemo natikambo-kambowamo. 'kalau saya punya anak sudah besar akan bertuan pada raja-raja'. Lirik ini menunjukkan ketulusan dan keikhlasan hati seorang ibu. Kesediaan berkorban dan mengabdi tidak hanya dimiliki oleh orangtua sendiri, tetapi termasuk mengajar dan mendorong keturunannya untuk mengabdi kepada golongan yang lebih tinggi. Jiwa pengabdian sudah ditanamkan oleh orangtua sejak anak dalam buaian. Jiwa pengabdian yang ditanamkan sejak kecil diharapkan dapat mengarahkan si anak agar mengikuti aturan yang telah ditetapkan oleh pemerintahnya.

Pada lirik berikutnya, nabhalamo namandemo natiala ngkawasamo 'besarlah dan menjadi pandai supaya bisa mengambil pekerjaan yang lain'. Lirik ini mengandung harapan orangtua agar kelak si anak dapat tumbuh dewasa menjadi orang yang pandai dan mempunyai pekerjaan yang layak. Anak adalah masa depan orangtua. Semua orangtua menginginkan anaknya memperoleh penghidupan yang layak agar kelak bisa membantu orang tuanya yang sudah mulai tua.

Kata pandai yang diwakili oleh kata namandhemo adalah kata yang bermakna luas. Kata ini juga bisa bermakna kreatif karena diikuti oleh frasa natiala ngkawasamo 'supaya bisa saja mengambil pekerjaan yang lain'. Ibu menyanyikan lagu buaian ini dan berharap agar anaknya kelak dapat menjadi anak yang tidak puas dengan kehidupan yang telah ditakdirkan kepadanya. Selain kreatif, secara keseluruhan nyanyian ini mendorong anak agar memiliki semangat pantang menyerah dengan level sosial yang dimilikinya.

\subsection{Nilai Karakter Bangsa dalam Nyanyian Pengantar Tidur secara Umum}

Nyanyian pengantar tidur berikut termasuk salah satu nyanyian pengantar tidur yang sering dilantunkan untuk menidurkan anak tanpa melihat kelas sosial. Ini berarti bahwa masyarakat secara umum bisa 
menyanyikan lagu ini. Berikut kutipan nyanyian rakyat tersebut.

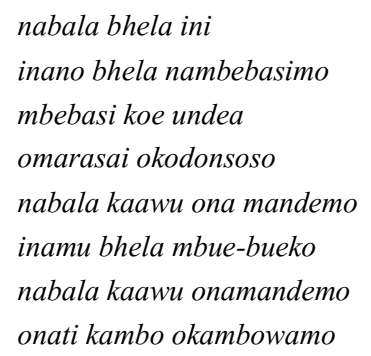

Terjemahan

kalau sudah besar ini

mamanya akan bahagia

senang jangan terlalu bersorak

susah jangan terlalu bersedih

hai, buyung, tidurlah nyenyak

mamamu membuai-buaimu

bila dewasa jadilah orang pandai

ajaklah mama ke mana pergi

Dalam syair nyanyian di atas, diungkapkan bahwa seorang ibu akan merasa sangat bahagia jika melihat anaknya dapat tumbuh dewasa menjadi orang pandai. Melalui ungkapan mbebasi koe undea 'senang jangan terlalu bersorak', omarasai okodonsoso 'susah jangan terlalu bersedih', orangtua memberi nasihat agar anak dapat menjadi orang yang bijaksana, selalu mawas diri, dan bersikap dewasa. Kesenangan yang diterima hendaknya tidak membuat seorang anak menjadi lupa diri, menjadi bangga, sombong, atau tinggi hati. Kebahagian dalam hidup menjadi sesuatu yang harus disyukuri. Dengan demikian, sikap waspada dan kontrol diri bisa tetap melekat dalam diri anak. Demikian pula sebaliknya, cobaan kesusahan dan kesedihan tidak disikapi dengan rasa sedih yang berlebihan. Kesedihan hendaknya dijadikan pelajaran untuk selalu berhati-hati dalam bertindak sehingga tidak berujung pada kesalahan dalam melangkah.

Selanjutnya, pada lirik nabala kaawu onamandemo 'bila dewasa jadilah orang pandai', tertuang harapan si ibu kepada sang buah hati agar kelak sang anak dapat menjadi orang yang berhasil. Ungkapan onati kambo okambowamo 'ajaklah mama ke mana pergi', mengandung harapan agar anak menjadi orang yang berhasil. Si anak diharapkan tidak hanya mampu berkembang di daerah sendiri, tetapi dapat berkiprah pula di tempat lain sehingga dapat pula membawa ibunya untuk berjalan-jalan melihat negeri orang. Kalimat ini mendorong anak untuk lebih kreatif dan selalu bekerja keras dalam menghadapi kehidupan.

Keinginan ibu untuk memberikan stimulus kebaikan sebelum tidur ternyata juga disarankan oleh pakar psikologis anak saat ini. Sentuhan dan belaian yang menyertai lagu buaian sebelum tidur adalah cara paling efektif untuk mengalirkan nilai-nilai kebaikan.

\subsection{Nilai Karakter Bangsa dalam Nyanyian Orangtua untuk Anak}

Nyanyian orangtua untuk anak termasuk jenis nyanyian liris sesungguhnya; biasanya tergolong jenis nyanyian yang berisi ungkapan perasaan yang sangat mendalam, seperti cinta kasih, kerinduan, rasa kehilangan, dan sebagainya. Nyanyian ini biasa dinyanyikan oleh para orangtua tentang anaknya. Sengaja dinyanyikan sebagai ungkapan curahan cinta dan kasih orangtua pada anaknya. Berikut kutipan nyanyian tersebut.

nabalano nemandemo

la ana wa ana

ambue-mbueko

natiara laangka wasamo

la ana wa ana

ae lau-lagu angko

amampeko tetana mbu-mbuku

amolateko nebakeku

tumolaangko nekawasano

nalomoa loaku ghule

to malanimo saide tomakule

ane mani nabala na mande

soka lolino bhuku maani

rumato neoa lea hitu

Terjemahan

sayangku kepada anak-anak

sayangku hai anak-anak

saya timang-timang

jika kau besar nanti

sayangku hai anak-anak

saya nyanyikan

saya angkat di ubun-ubunku

kutempatkan di hatiku

saya berdoa pada Tuhanku 
agar terlepas dari mulut ular

begitulah cita-cita kami kami orangtuamu

anak kami besar dan pandai

untuk pengganti generasi penerus

setelah kami tak kuat lagi

Nyanyian orangtua untuk anak tergolong jenis nyanyian yang berisi ungkapan perasaan yang sangat mendalam, seperti cinta kasih, kerinduan, rasa kehilangan, dan sebagainya. Nyanyian jenis ini sengaja dinyanyikan sebagai ungkapan curahan cinta dan kasih orangtua pada anaknya. Nyanyian tersebut menggambarkan ungkapan perasaaan kasih sayang yang dimiliki oleh seorang ibu kepada anaknya. Anak merupakan buah hati, pelepas lelah, penerus keturunan, dan harapan orangtua di masa depan. Nyanyian berikut mengungkapkan perasaan sayang orangtua kepada anaknya. Waktu kecil seorang anak ditimang-timang. Orangtua berusaha menumpahkan kasih sayangnya kepada anak. Anak dibelai dan dibuai oleh orangtua. Segenap kemampuan dikerahkan untuk memenuhi kebutuhan si anak. Lirik tumolaangko nekawasano 'saya angkat di ubun-ubun', nalomoa loaku ghule 'kutempatkan di hatiku' menggambarkan posisi anak bagi orangtua. Anak menempati tempat yang istimewa di hati mereka. Anak menjadi harapan bagi orangtua untuk menjadi generasi penerus dan harapan pengasuhan jika kelak mereka sudah tua.

Kalimat to malanimo saide tomakule 'begitulah citacita kami kami orangtuamu' dan ane mani nabala na mande 'anak kami besar dan pandai' adalah dua kalimat harapan orangtua terhadap anaknya agar kelak menjadi anak yang mandiri dan kreatif sehingga mereka dapat memperbaiki nasib keluarga mereka. Orangtua merangsang anak agar selalu mencari cara terbaik agar suatu saat dapat menjadi generasi penerus yang dapat memperbaiki kualitas kehidupan mereka. Makna tersebut juga mewakili kalimat soka lolino bhuku maani 'untuk pengganti generasi penerus' dan rumato neoa lea hitu 'setelah kami tidak kuat lagi'.

\subsection{Nilai Karakter Bangsa dalam Nyanyian Anak untuk Orangtua}

Perasaaan kasih sayang dan rasa rindu seorang anak terhadap orangtua seringkali diungkapkan lewat lirik- lirik lagu yang bisa meneteskan air mata, menggemuruhkan perasaan ataupun membuat hati menjadi lapang. Dalam NRM, hal demikian pun dapat dijumpai. Seorang anak mengungkapkan perasaan terhadap orangtuanya. Dalam contoh nyanyian berikut si anak menyanjung orangtuanya sebagai orang yang berhati manikam (bofe lalo manikami). Dapat dilihat juga pada contoh nyanyian Kaninindo Kamokula 'Kasih Sayang ke Orangtua' berikut ini.

\section{Kaninindo Kamokula \\ afekiri ka asindo \\ inaku amaku \\ laloku ira \\ bofe lalo manikami \\ ko rudu wa hando}

Terjemahan

Kasih Sayang ke Orangtua

kuingat kasih sayang orangtua

ibuku, ayahku

hatiku tersayat-sayat

berhati manikam

kedua-duanya

Nyanyian ini menunjukkan adanya pemberian simbol. Nyanyian tersebut mengungkapkan perasaan seorang anak kepada orangtuanya. Manikam termasuk batu perhiasan yang sangat indah dan mahal. Begitu besar perasaan kasih sayang yang diterima oleh si anak dari orangtuanya hingga ia melihat orangtuanya sebagai orang yang mempunyai hati yang baik dan rela berkorban untuk kebahagiaan anak-anaknya. Jika mengingat hal-hal tersebut, akan timbul rasa sedih di hati si anak seperti sedang tersayat-sayat. Pada lirik laloku ira 'hatiku tersayat-sayat', kepedihan yang dirasakan si anak seringkali terjadi karena si anak merasa bahwa dirinya belum dapat membalas pengorbanan dan kasih sayang yang telah diberikan oleh orangtuanya kepada dirinya. Apalagi jika si anak harus hidup jauh dari orangtua yang sudah semakin renta.

Pernyataan anak yang diungkapkan lewat syair lagu adalah sebuah janji anak kepada kedua orangtuanya. Anak yang selalu mengingat kasih sayang dan pengorbanan kedua orangtua termasuk kriteria anak 
yang akan berhasil suatu hari nanti. Kasih sayang ini akan memotivasinya untuk melakukan yang terbaik demi kebahagiaan kedua orangtuanya. Kasih sayang ini pula yang mendorongnya untuk selalu bekerja keras dalam setiap usaha yang dilakukannya.

\section{PENUTUP}

Nyanyian rakyat Muna yang berfungsi sebagai nyanyian pengantar tidur mengandung nilai-nilai karakter bangsa yang mengarahkan seorang anak agar jujur, tidak korupsi, dan tidak tawuran massal. Selain dalam nyanyian pengantar tidur, nilai karakter bangsa juga ditemukan dalam nyanyian nasihat orangtua kepada anak dan nyanyian yang mengungkapkan kasih sayang anak pada orangtuanya. Kedua jenis nyanyian ini mengarahkan anak agar selalu kreatif, selalu bekerja keras, dan mandiri.

Nyanyian rakyat Muna adalah kekayaan budaya yang perlu kita lestarikan. Penulis berharap telaah terhadap kekayaan budaya ini dapat dilanjutkan demi menemukan nilai-nilai kehidupan yang dapat kita terapkan dalam keseharian kita agar nyanyian ini tidak selamanya menjadi sastra lisan. Selain itu, pemerintah daerah perlu mengembangkan bahan ajar muatan lokal agar nilai-nilai luhur didalamnya tidak tergerus oleh modernisasi.

\section{DAFTAR PUSTAKA}

Aziz, Hamka. 2011. Pendidikan Karakter Berpusat pada Hati. Jakarta: Al-Mawardi Prima.

Binus. 2010. "Pendapat Para Ahli tentang Pendidikan," dalam http://library.binus.ac.id/eColls/Thesis/Bab2/2010-200127-ds\%20bab202.pdf, diakses 18 September 2012.

Danandjaja, James. 1986. Folklor Indonesia. Jakarta: Pustaka Grafitipers.

Khan, D. Yahya. 2010. Pendidikan Karakter Berbasis Potensi Diri: Mendongkrak Kualitas Pendidikan. Yogyakarta: Pelangi Publishing.

Kompas. 2009. "Tawuran antar Warga Marak Terjadi," dalam http://nasional.kompas.com/read/2010/09/30/0350573/Tawuran.antar.Warga.Marak.Terjadi, diakses 17 September 2012.

Kompas. 2010. “Anak SMP Kok Bawa Celurit,” dalam http://nasional.kompas.com/read/2011/04/02/08445551.Pelajar.ke.Sekolah. Kok.Bawa.Celurit, diakses 17 September 2012.

Rahmawati, dkk. 2010. “Tinjauan Hermeneutika terhadap Nyanyian Rakyat Muna,” Laporan Penelitian Tim Sastra Kantor Bahasa Provinsi Sulawesi Tenggara. Kendari: Kementerian Pendidikan Nasional.

Raka, Gede. 2011. Pendidikan Karakter di Sekolah. Jakarta: PT Gramedia.

Ratna, Nyoman Kutha. 2005. Sastra dan Cultural Studies Representasi Fiksi dan Fakta. Yogyakarta: Pustaka Pelajar.

Rumah Inspirasi. 2011. "Nilai dalam Pendidikan Karakter Bangsa," dalam http://rumahinspirasi.com/18-nilai-dalampendidikan-karakter-bangsa/, diakses 17 September 2012.

Sardiman, A.M. 2006. Interaksi dan Motivasi Belajar Mengajar. Jakarta: PT Raja Grafindo Persada.

Untoro, R. 2009. "Memahami Karya Sastra Postmodern melalui Pembacaan Dekonstruksi Derrida," dalam Widyariset Vol. 12, No. 3, hlm. 75-82. 
Mulawati : Nilai Karakter Bangsa dalam Nyanyian Rakyat Muna

Takari, Muhammad. 2013. "Tradisi Lisan Di Alam Melayu Arah dan Pewarisannya," dalam www.researchgate.net/Tradisi_Lisan/00b4952a47f49bf7860000, diakses 5 Desember 2014. 